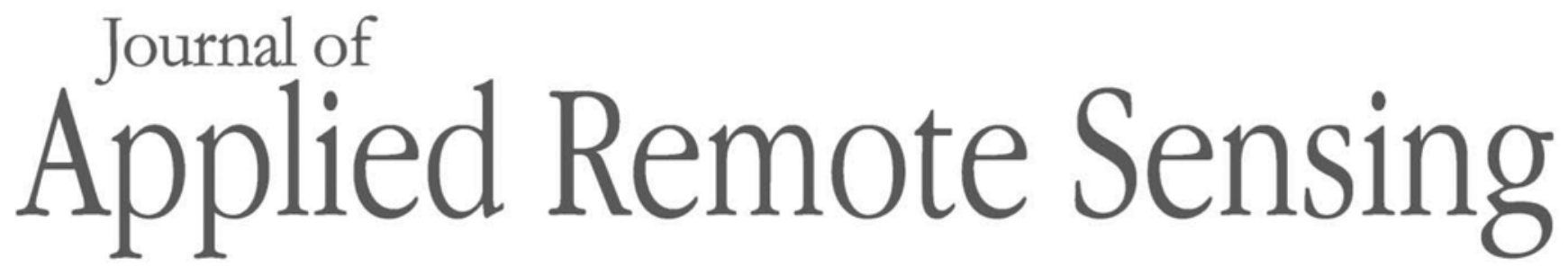

RemoteSensing.SPIEDigitalLibrary.org

\title{
Mangrove vegetation structure in Southeast Brazil from phased array L-band synthetic aperture radar data
}

Francisca Rocha de Souza Pereira Milton Kampel

Marilia Cunha-Lignon 


\title{
Mangrove vegetation structure in Southeast Brazil from phased array L-band synthetic aperture radar data
}

\author{
Francisca Rocha de Souza Pereira, ${ }^{\text {a,* }}$ Milton Kampel, ${ }^{\text {a }}$ and \\ Marilia Cunha-Lignon ${ }^{b}$ \\ ${ }^{a}$ National Institute for Space Research, Remote Sensing Division, Av. dos Astronautas, \\ 1758, São Jose dos Campos 12227-010, Brazil \\ ${ }^{\mathrm{b}}$ Universidade Estadual Paulista, Campus Experimental de Registro, Rua Nelson Brihi Badur, \\ 430, Registro, São Paulo 11900-000, Brazil
}

\begin{abstract}
The potential use of phased array type L-band synthetic aperture radar (PALSAR) data for discriminating distinct physiographic mangrove types with different forest structure developments in a subtropical mangrove forest located in Cananéia on the Southern coast of São Paulo, Brazil, is investigated. The basin and fringe physiographic types and the structural development of mangrove vegetation were identified with the application of the Kruskal-Wallis statistical test to the SAR backscatter values of 10 incoherent attributes. The best results to separate basin to fringe types were obtained using copolarized $\mathrm{HH}$, cross-polarized $\mathrm{HV}$, and the biomass index (BMI). Mangrove structural parameters were also estimated using multiple linear regressions. BMI and canopy structure index were used as explanatory variables for canopy height, mean height, and mean diameter at breast height regression models, with significant $R^{2}=0.69,0.73$, and 0.67 , respectively. The current study indicates that SAR L-band images can be used as a tool to discriminate physiographic types and to characterize mangrove forests. The results are relevant considering the crescent availability of freely distributed SAR images that can be more utilized for analysis, monitoring, and conservation of the mangrove ecosystem. (C) The Authors. Published by SPIE under a Creative Commons Attribution 3.0 Unported License. Distribution or reproduction of this work in whole or in part requires full attribution of the original publication, including its DOI. [DOI: 10.1117/1.JRS.10.036021]
\end{abstract}

Keywords: mangrove; vegetation structure development; physiographic types; synthetic aperture radar; phased array type L-band synthetic aperture radar.

Paper 15803 received Nov. 16, 2015; accepted for publication Aug. 10, 2016; published online Sep. 6, 2016.

\section{Introduction}

In tropical and subtropical regions, disordered urban occupancy and land use of coastal zones have caused the degradation of typical ecosystems like mangroves. Mangroves are key coastal ecosystems, providing conditions for food, protection, and reproduction for many animal species as well as other numerous environmental services. ${ }^{1}$ Mangroves also help to protect the coast against the forces of waves, tides, and tsunamis, curbing erosion of shorelines. ${ }^{2}$ The structural characterization of mangroves allows the analysis of their health and contributes to monitoring efforts. Mangrove forest structure data of the southeast coast of Brazil was analyzed, and it was noted that the characterization and monitoring of this ecosystem is important to assist with management planning for this area.,

The development of a mangrove's forest structure is associated with the intensity and frequency of environmental factors. ${ }^{5,6}$ Generally, the maximum structural development of mangrove forests occurs in regions where appropriate topography is subject to large tidal range, ample freshwater input, precipitation, nutrients, and sediments. ${ }^{5,6}$ A classification of mangroves based on physiographic and structural attributes was first presented by Lugo and Snedaker. ${ }^{7}$ Schaeffer-Novelli et al. ${ }^{8}$ suggested a classification in two main types, according to their physiographic characteristics: fringe and basin forests. This classification approach is more related to

*Address all correspondence to: Francisca Rocha de Souza Pereira, E-mail: franrspereira@gmail.com, fran@dsr.inpe.br 
local hydrodynamics. The fringe type occurs along the edge of the estuary and receives more frequent flooding, presenting high levels of structure development. Basin forest type occupies land areas with less frequent flooding and presents a less developed structure. Discriminating basin and fringe mangroves indicates differences in size, composition, and productivity and, therefore, carbon storage.

Considering the importance of mangroves for the coastal zone, its characterization, conservation, and monitoring become crucial. The use of remote sensing techniques for the measurement, monitoring, and reporting of structure, biomass, ${ }^{9-11}$ and carbon stocks in forests seems to be a valuable and low-cost tool when compared to field survey. ${ }^{12,13}$ Different techniques and data are used to detect mangrove-forest changes, species diversity, structural characterization, biomass estimation, mapping, quantifying, and qualifying mangrove forests using optical imagery, ${ }^{14-16}$ light detection and range data, ${ }^{17-19}$ and synthetic aperture radar (SAR) imagery. SAR data have been used mainly for mapping mangrove area, biomass estimations, and structural analysis of mangrove forests. ${ }^{20-27}$ SAR is an active microwave sensor that allows the penetration of the incident signal through the forest canopy. The penetration and interaction of the incident signal and the intensity of the backscattered signal is dependent on the characteristics of the SAR sensor itself, in terms of its frequency or wavelength, polarization, and incidence angle as well as on the parameters of the studied target, such as its dielectric constant, rugosity, and geometry. The penetration of the SAR microwaves through the canopy is dependent on these characteristics, and when it occurs, it allows information about the vegetation structure of mangrove forests to be obtained. C-band SAR pulses interact mainly with the leaves and the superficial crown of the tree, while the L-band interaction occurs on the canopy, leaves, branches, trunks, and trunks-ground interaction. The backscattered signal from the forest includes components of many scattering mechanisms, such as scattering of the canopy, volumetric scattering, double-bounce, superficial scattering, and interaction with the ground and trunks. ${ }^{28}$ The forest backscatter also varies according to soil moisture, as in the case of wetlands like mangroves. The backscatter increases due to the interaction between the flooded soil and trunks, resulting in the double bounce scattering. ${ }^{29,30}$ SAR imaging in P- and L-bands is more susceptible to variations in mangrove biomass. ${ }^{21,24}$ Spaceborne X- and C-band SAR sensors, together with other optical sensors have been available to provide data for observing and quantifying changes in mangroves. ${ }^{18,19,22,27}$ However, the L-band SAR has a relatively better capacity to support mangrove monitoring efforts at a global scale, ${ }^{26}$ providing consistent, systematic and cloud-free observations with a greater sensitivity to the three-dimensional woody components of mangroves which is good for estimating above-ground biomass and structure. ${ }^{20}$ Even though other SAR systems provide data that support different mangrove studies, L-band SAR can supply more information for under way monitoring on a global scale. ${ }^{26}$ Considering the relative scarcity of SAR studies that investigate the structural characteristics of basin and fringe mangroves, the present study aims to evaluate the use of advanced land observing satellite (ALOS) phased array type L-band SAR (PALSAR) data for discriminating distinct physiographic mangrove types with different forest structure developments in a subtropical mangrove forest located in Cananéia on the southern coast of São Paulo, Brazil. The relationships between the different mangrove structural parameters and SAR backscatter values of 10 incoherent attributes using statistical regression models were also evaluated.

\section{Experimental Section}

\subsection{Study Area and Data Acquisition}

The study area is located within the Cananéia-Iguape Coastal System on the southern coast of São Paulo, Brazil, between the latitudes $24^{\circ} 40^{\prime} \mathrm{S}$ to $25^{\circ} 19^{\prime}$ S. According to Köppen's classification, this area is characterized as a humid tropical climate. The mangrove vegetation typically found in this region includes Rhizophora mangle L., Avicennia schaueriana Stapf. \& Leechman, and Laguncularia racemosa (L.) Gaertn. F. This region has a recognized ecological importance and is protected by environmental laws in Brazil, such as the federal law 12.651/12 (Brasil. Law no. 12.651/12 of 25/05/2012). This sector of the coast contains the most conserved mangrove 


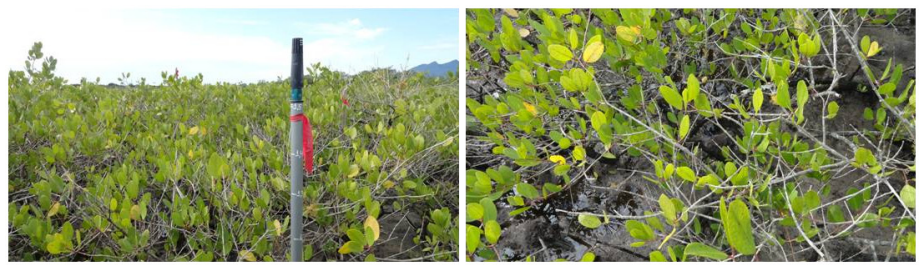

(a)

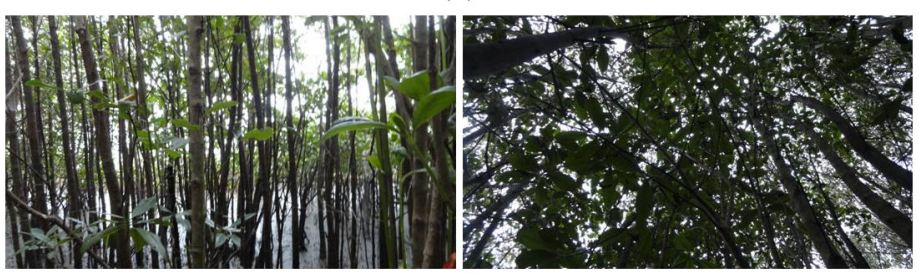

(b)

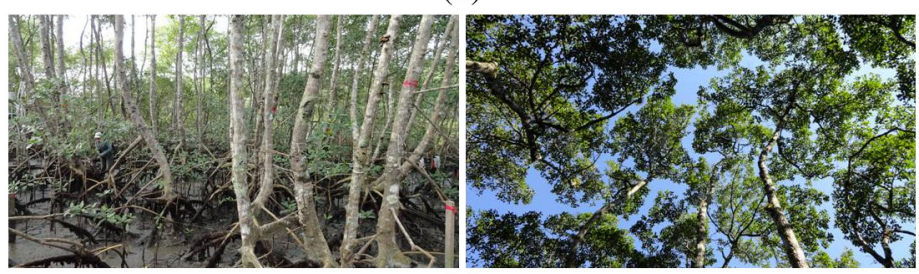

(c)

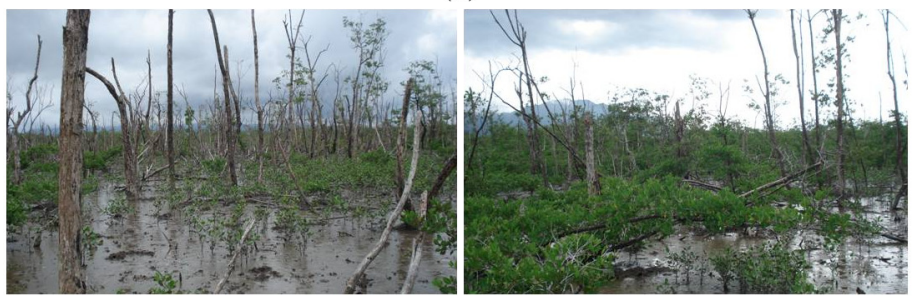

(d)

Fig. 1 Example of physiographic types and structural development of mangrove forests occurring in the study area: (a) basin, (b) progradation fringe, (c) mature fringe, and (d) gap (photos obtained in January 2010).

ecosystem in the state of São Paulo. ${ }^{3}$ It has also been reported that mangroves in this area grow at rates of $\sim 80 \mathrm{~cm} /$ year in the early stages of development in depositional areas. ${ }^{4}$

A total of 16 stands were defined, representing distinct physiographic types at different stages of development of vegetation structure: (1) progradation fringe, (2) mature fringe, (3) basin, and (4) gap (Fig. 1). The structural parameters of 16 stands of mangrove vegetation (Table 1) were formed by grouping similar mangrove plots. All the data on mangrove structure were obtained from the studies of Coelho, ${ }^{31}$ Cunha-Lignon et al. ${ }^{3,32}$ and from a field campaign held in 2010. The acquisition of data on mangrove vegetation structure followed the methodology proposed by Cintrón and Schaeffer-Novelli. ${ }^{33}$ Plot sizes varied according to stem density. In each plot, all plants were identified and the diameter at breast height $(\mathrm{DBH})$ and height were recorded. Mean DBH, basal area dominance, and stem density were calculated.

\subsubsection{Mangrove structure}

Mangrove zonation patterns are the response of depositional, erosive, and topographic processes. ${ }^{3}$ Representative physiographic mangrove types in the study site are shown in Fig. 1. The basin stands $(5,10,11$, and 14) showed a high density of trees, small structural development, median value of canopy height $(\leq 3.5 \mathrm{~m})$, thin and low trunks, and a low value for mean $\mathrm{DBH}$. Basin mangrove stands occupied areas with lower frequent flooding and poor nutrients in soil, and presented a higher density of small trunks with many ramifications. ${ }^{31}$ The fringe in the progradation type identified in stands 1,3 , and 6 was constituted by young trees with canopy heights ranging from 3 to $8.8 \mathrm{~m}$, a high density of trees with thin trunks, and $\mathrm{DBH}$ ranging from 1.25 to 
Table 1 Forest structure data of 16 mangrove stands obtained from previous studies. $3,4,31$ $L$. racemosa $(\mathrm{Lg}), A$. schaueriana $(\mathrm{Av}), R$. mangle $(\mathrm{Rh})$. Fringe progradation: stands 1 , 3, and 6; mature fringe: stands $2,4,7,8,9,12,13$, and 16; basin: stands 5, 10, 11, and 14; and gap: stand 15.

\begin{tabular}{|c|c|c|c|c|c|c|c|}
\hline $\begin{array}{l}\text { Physiographic } \\
\text { types of } \\
\text { mangroves }\end{array}$ & Stand & $\begin{array}{l}\text { Dominant } \\
\text { species }\end{array}$ & $\begin{array}{c}\text { Mean } \\
\text { DBH }(\mathrm{cm})\end{array}$ & $\begin{array}{c}\text { Canopy } \\
\text { height }(\mathrm{m})\end{array}$ & $\begin{array}{l}\text { Density } \\
\text { (trunk/ha) }\end{array}$ & $\begin{array}{c}\text { Basal } \\
\text { area }\left(\mathrm{m}^{2} / \mathrm{ha}\right)\end{array}$ & $\begin{array}{c}\text { Mean } \\
\text { height }(\mathrm{m})\end{array}$ \\
\hline \multirow{3}{*}{$\begin{array}{l}\text { Fringe progradation } \\
\text { stands }\end{array}$} & 1 & $\operatorname{Lg}$ & 3.06 & 5.90 & 93512.50 & 36.79 & 4.75 \\
\hline & 3 & $\mathrm{Lg}$ & 2.71 & 6.89 & 76111.11 & 41.44 & 3.79 \\
\hline & 6 & $\mathrm{Rh}$ & 3.00 & 5.25 & 48625.00 & 22.21 & 3.89 \\
\hline \multirow{8}{*}{$\begin{array}{l}\text { Mature fringe } \\
\text { stands }\end{array}$} & 2 & $A v$ & 13.91 & 13.66 & 2266.67 & 27.09 & 9.65 \\
\hline & 4 & $\mathrm{Rh}$ & 10.31 & 11.60 & 3800.00 & 28.42 & 6.23 \\
\hline & 7 & $\mathrm{Rh}$ & 6.64 & 12.20 & 11600.00 & 40.19 & 3.97 \\
\hline & 8 & $\mathrm{Rh}$ & 5.95 & 8.70 & 13299.00 & 23.95 & 3.55 \\
\hline & 9 & $\mathrm{Rh}$ & 7.45 & 8.80 & 12655.50 & 34.50 & 3.00 \\
\hline & 12 & $\mathrm{Rh}$ & 10.03 & 8.87 & 8341.67 & 27.33 & 3.67 \\
\hline & 13 & $\mathrm{Rh}$ & 9.60 & 7.70 & 9247.33 & 29.33 & 4.03 \\
\hline & 16 & Lg. Av & 14.23 & 13.16 & 1952.66 & 29.07 & 7.88 \\
\hline \multirow[t]{4}{*}{ Basin } & 5 & $\mathrm{Lg}$ & 1.78 & 1.47 & 84762.00 & 21.69 & 1.47 \\
\hline & 10 & $\mathrm{Lg}$ & 4.58 & 3.23 & 20413.00 & 15.88 & 2.13 \\
\hline & 11 & $\mathrm{Rh}$ & 4.37 & 3.13 & 23066.67 & 13.47 & 1.91 \\
\hline & 14 & $\operatorname{Lg}$ & 2.11 & 1.40 & 73333.00 & 24.50 & 1.40 \\
\hline Gap & 15 & $A v$ & 3.14 & 5.30 & 14000.00 & 24.90 & 2.40 \\
\hline
\end{tabular}

$4.5 \mathrm{~cm}$. The third physiographic type identified in the study site corresponds to mature fringe stands $(2,4,7,8,9,12,13$, and 16). These mangrove stands are structurally well developed and show a low density of trees, with canopy heights reaching $14 \mathrm{~m}$, and mean DBH ranging from 6 to $14 \mathrm{~cm}$. Stand 15 was characterized by a large gap area with dead and young trees. In this gap area, exposed soil ${ }^{31}$ was also observed.

\subsection{Synthetic Aperture Radar Image Processing}

The original image used in this investigation was a polarimetric ALOS-PALSAR, level 1.1, which was in the single look complex format and contains radiometric and phase signals, with full quad-polarization $(\mathrm{HH} / \mathrm{HV} / \mathrm{VH} / \mathrm{VV})$. The main characteristic of the image is shown in Table 2 . The tide height was $\sim 0.9 \mathrm{~m}$ at the moment of the PALSAR image acquisition. Therefore, the mangrove soil surface was flooded. There was no accumulated rainfall in the last $24 \mathrm{~h}^{34}$

The polarimetric SAR image (originally in scattering matrix format) that contains the coherent polarimetric phase and amplitude information of the radar signal in all polarization was preprocessed first to reduce speckle noise. The speckle is a variation in backscatter caused by the random fluctuations in strength of the return signal. ${ }^{35} \mathrm{~A}$ speckle polarimetric filter was applied according to Lee et al., ${ }^{36}$ using a $5 \times 5$ pixel window. The result was a filtered image in covariance matrix format [C4]. The multilook SAR processing is a technique to reduce speckle and data compression and it may be modeled by averaging some neighboring one-look pixels. This speckle filter allows the reduction of the speckle in the image and the preservation of the polarimetric and spatial information of the original SAR image. According to Lee et al., ${ }^{36}$ it is necessary to filter (in a manner similar to multi-look processing) each term of the covariance matrix by 
de Souza Pereira, Kampel, and Cunha-Lignon: Mangrove vegetation structure in Southeast Brazil...

Table 2 Characteristics of the PALSAR image used in this study.

\begin{tabular}{lc}
\hline \hline Sensor & ALOS-PALSAR \\
\hline Frequency $(\mathrm{Ghz})$ & 1.2 \\
Wavelength $(\mathrm{cm})$ & 23.6 \\
Polarization & $\mathrm{HH} / \mathrm{HV} / \mathrm{VH} / \mathrm{VV}$ \\
Mode & Polarimetric \\
Process level & 1.1 \\
Azimuth view & Ascendant \\
Time of image acquisition & June $8,2009,02: 10 \mathrm{GMT}$ \\
Angle of incidence & 25.7 deg \\
Original spatial resolution $($ slant. $\times$ az.) $(\mathrm{m})$ & $9.4 \times 4.5 \mathrm{~m}$ \\
Pixel size & $9.4 \times 3.8 \mathrm{~m}$ \\
Swath & $\sim 30 \mathrm{~km}$ \\
\hline \hline
\end{tabular}

averaging the covariance matrices of neighboring pixels. After being filtered, the multipolarized intensity images ( $\mathrm{HH}, \mathrm{HV}, \mathrm{VH}$, and VV) were extracted. The image in slant range format was converted to ground range format using sensor parameters, satellite height, size of pixel in range, and azimuth information. ${ }^{37}$ Geometric correction was performed with the rational function model, which is based on polynomial adjustment, using 16 ground control points (GCP) obtained in the field and a digital topographic map (SG-23-V-A-IV-3 Ilha de Cananéia) from the Instituto Brasileiro de Geografia e Estatistica. The pixel was resampled to $12.5 \mathrm{~m}$ and used the Universal Transverse Mercator projection (Datum SAD 69, zone 23) during the geometric correction step. The root-squared-mean error (RMSE) obtained in this processing was $10.15 \mathrm{~m}$. To evaluate the quality of geometric correction, a comparison based on the geospatial positioning accuracy standards approach ${ }^{38}$ was made with independent check points, with an RMSE of $19.13 \mathrm{~m}$ that was considered acceptable.

The total power received at the SAR sensor is related to the energy return of the illuminated area. The strength of the energy return depends on the orientation, roughness, electrical properties of the surface, and the polarization direction of the returning SAR pulse. The radar-scattering coefficient is the radar scattering per unit area. ${ }^{35}$ The digital number (DN) value in each pixel was converted to the backscatter coefficient $\left(\sigma^{\circ}\right)$ in sigma nought according to Eq. (1), ${ }^{39}$ where $f c$ is the calibration factor equal to -83 and $A^{39}$ is the conversion factor equal to 32 :

$$
\sigma^{\circ}=10 * \log (\mathrm{DN})+f c-A
$$

Following sigma nought conversion of the $\mathrm{HH}, \mathrm{HV}, \mathrm{VH}$, and VV images, incoherent attributes were derived from radar power measurements in $\sigma^{\circ}$ using a linear scale format. A total of 10 attributes were extracted. These included the backscatter coefficients $\left(\sigma^{0}\right)$ for the polarizations $\mathrm{HH}, \mathrm{HV}, \mathrm{VV}$, the parallel polarization ratio $(\mathrm{Rp}),{ }^{35}$ the cross-polarization ratio $(\mathrm{Rc}),{ }^{35}$ the total power $(\mathrm{Pt})$, and the Pope SAR vegetation index, ${ }^{40}$ such as biomass index (BMI), canopy structure index (CSI), and volume scattering index (VSI; Table 3). The average of HV and VH was used for cross polatization. The Pt is the sum of the backscatter in all polarizations including all scattering mechanisms. The Rp is related to the shape and orientation of the scattering elements of the forest. Rc $(\mathrm{HV} / \mathrm{VV}$ and $\mathrm{HV} / \mathrm{HH})$ is the ratio that is related to the amount of scattering from small forest elements, which depolarizes the signal relative to the scatter of large surfaces and double bounce scattering. ${ }^{35}$ Low values of Rc indicated significant surface scattering, corner reflector effects while high values indicated volume scattering. The biophysical indices developed by Pope et al. ${ }^{40}$ have advantages over individual parameters. Most of the biophysical indices, based on ratios or normalized differences, are independent of terrain slopes or range effects. 
de Souza Pereira, Kampel, and Cunha-Lignon: Mangrove vegetation structure in Southeast Brazil...

Table 3 SAR incoherent attributes equation according to Henderson and Lewis $^{35}$ and Pope et al. ${ }^{40}$

\begin{tabular}{lccc}
\hline \hline SAR incoherent attributes & Equation & SAR incoherent attributes & Equation \\
\hline Parallel polarization ratio & $\frac{\mathrm{VV}}{\mathrm{HH}}$ & $\mathrm{BMI}$ & $\frac{\mathrm{HH}+\mathrm{VV}}{2}$ \\
Cross-polarization ratio & $\frac{\mathrm{HV}}{\mathrm{VV}} ; \frac{\mathrm{HV}}{\mathrm{HH}}$ & Canopy structure index (CSI) & $\frac{\mathrm{VV}}{\mathrm{HH}+\mathrm{VV}}$ \\
Total power (Pt) & $\mathrm{HH}+\mathrm{HV}+\mathrm{VH}+\mathrm{VV}$ & Volume scattering index (VSI) & $\frac{(\mathrm{HV}+\mathrm{VH})}{2}$ \\
& & & $\frac{\mathrm{HV}+\mathrm{VH})}{2}+\frac{(\mathrm{VV}+\mathrm{HH})}{2}$ \\
\hline \hline
\end{tabular}

For L-band SAR, the indices are related to the upper canopy, trunk, and branching characteristics, also depending on the vegetation type. ${ }^{40}$ The VSI is a measure of the depolarization of linearly polarized signals and an indirect measure of the number of canopy-scattering elements. The CSI indicates the relative importance of vertical versus horizontal structures in forest. The $\mathrm{BMI}$ is an indicator of the quantity of wood in contrast to leafy biomass. ${ }^{40}$

Polygons representing the 16 mangrove stands were obtained using GCPs for each stand. The $\sigma^{\circ}$ values (in linear scale) of the 10 incoherent attributes were extracted from the 16 polygons in the SAR image (Fig. 2). The average value of $\sigma^{\circ}$ in linear scale referred to each polygon was transformed to decibel scale $(\mathrm{dB})$ according to Eq. (2):

$$
\sigma^{\circ}(\mathrm{dB})=10 * \log 10\left(\sigma^{\circ} \text { linear }\right)
$$

\subsection{Synthetic Aperture Radar Statistical Analysis}

The differences among the backscatter value of incoherent attributes due to the different physiographic mangrove types and vegetal structure development were statistically verified using the Kruskal-Wallis nonparametric test. After this, a multicomparison test was applied to check if each incoherent attribute had enabled a statistically significant distinction. Thus, the differences between the physiographic mangrove types were statistically verified.

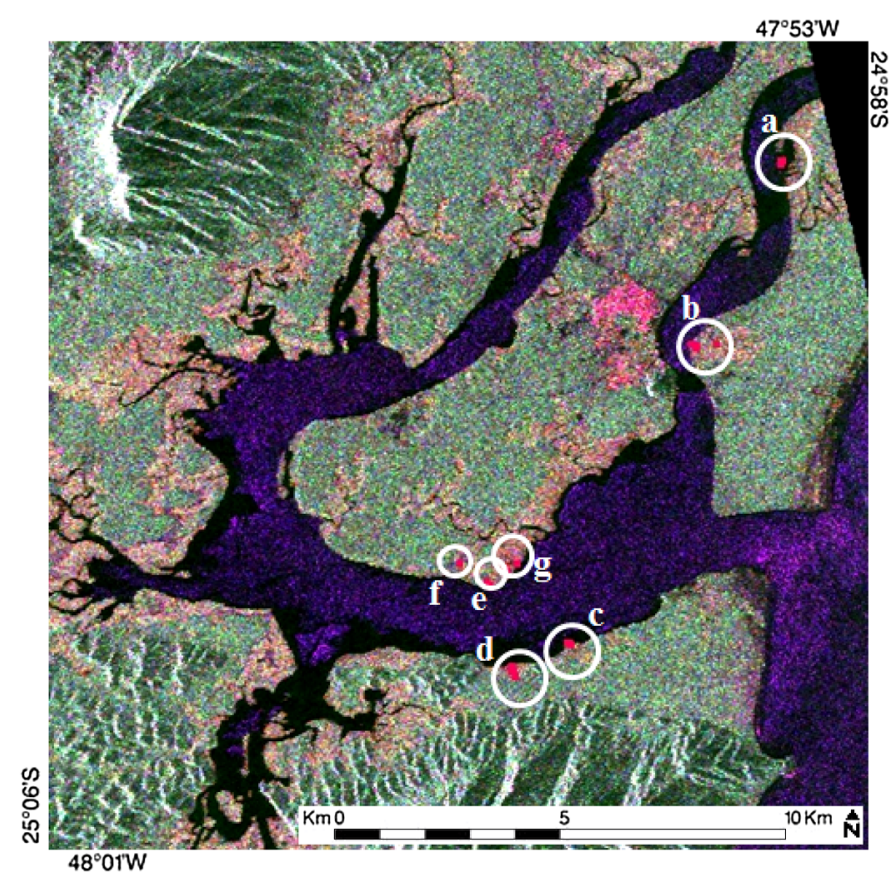

Fig. 2 Cananéia island, PALSAR image (June 8, 2009) color composition $R(H H) G(H V) B(V V)$; The stands' location are (a) stands 1 and 2; (b) stands 3, 4, 5; (c) stands 6 and 7; (d) stands 8, 9, 10, 11; (e) stands 12, 13; (f) stand 14; (g) gap-stands 15 and 16. 
Simple and multivariate linear regressions were applied in order to investigate the correlation between incoherent attributes and mangrove-structure parameters. The regression model is a way to statistically express the tendency of the variation of dependent variable $(Y)$ to predict the independent variable $(X){ }^{41}$ The stepwise forward and the best-subset methods ${ }^{41}$ were used to select the SAR predictors of the models. The criterion used for the selection of the regression function was analyzing the values from adjusted- $R^{2}$ and $R^{2}$; the low correlation between explanatory variables; and the function composed with fewer variables.

The identification of outliers was done by analyzing the studentized deleted residuals and leverage value of that matrix. ${ }^{41}$ Cook's distance method was used to analyze the influence of the outliers in the model. The normality of the regression residual was analyzed by the Shapiro-Wilk test. The validation of the models was performed using the predicted sum of squares (PRESS) statistic value. ${ }^{41}$

\section{Results and Discussion}

\subsection{Synthetic Aperture Radar Attributes Analysis}

This section intends to highlight the backscatter of SAR incoherent attributes that present the potential to distinguish the physiographic mangrove types, fringe and basin, and vegetation structure development, progradation and mature. The vegetation structure of these types of mangroves presented differences that could interact with SAR microwaves. Table 4 shows the value of SAR backscatter for 10 incoherent attributes ordained by physiographic mangrove types. The values of $\sigma^{\circ}$ in Table 4 are the average values of $\sigma^{\circ}$ for each mangrove stand and were calculated in linear scale and transformed to decibel scale $(\mathrm{dB})$. Figure 3 shows the results of the mean and standard deviation of the backscatter value of 10 incoherent attributes. Note that the attributes $\mathrm{HH}, \mathrm{Pt}$, and BMI allowed the discrimination of the basin type from fringe mangrove with $-2 \mathrm{~dB}$ of difference for $\mathrm{HH}$ mean with a higher value for the basin type. The HV polarization

Table 4 SAR backscatter values of physiographic mangrove types for 10 incoherent attributes, values $\sigma^{\circ}(\mathrm{dB})$ (see text for acronyms).

\begin{tabular}{|c|c|c|c|c|c|c|c|c|c|c|c|}
\hline $\begin{array}{l}\text { Physiographic } \\
\text { type }\end{array}$ & Stand & $\mathrm{HH}$ & HV & VV & $\mathrm{Pt}$ & BMI & CSI & VSI & HV/VV & $\mathrm{VV} / \mathrm{HH}$ & $\mathrm{HV} / \mathrm{HH}$ \\
\hline \multirow{3}{*}{$\begin{array}{l}\text { Fringe in } \\
\text { progradation }\end{array}$} & Stand 1 & -3.16 & -13.10 & -8.36 & -1.38 & -5.02 & -6.17 & -8.57 & -4.18 & -4.86 & -9.70 \\
\hline & Stand 3 & -2.45 & -11.72 & -3.37 & 0.66 & -2.89 & -3.51 & -8.76 & -6.80 & 0.00 & -8.08 \\
\hline & Stand 6 & -1.91 & -13.16 & -6.21 & -0.09 & -3.55 & -5.66 & -10.07 & -7.02 & -4.23 & -11.15 \\
\hline \multirow{8}{*}{$\begin{array}{l}\text { Mature } \\
\text { fringe }\end{array}$} & Stand 2 & -5.22 & -12.59 & -7.09 & -2.17 & -6.05 & -3.77 & -7.18 & -4.88 & -0.74 & -6.38 \\
\hline & Stand 4 & -2.21 & -9.95 & -3.20 & 1.08 & -2.68 & -3.56 & -7.69 & -5.51 & -0.16 & -6.87 \\
\hline & Stand 7 & -3.28 & -11.76 & -6.35 & -0.79 & -4.55 & -5.04 & -7.80 & -4.58 & -3.04 & -8.09 \\
\hline & Stand 8 & -2.54 & -9.82 & -5.18 & 0.29 & -3.66 & -4.40 & -6.79 & -3.94 & -2.23 & -6.32 \\
\hline & Stand 9 & -0.99 & -7.71 & -2.42 & 2.32 & -1.65 & -3.61 & -7.05 & -4.90 & -2.62 & -6.02 \\
\hline & Stand 12 & -3.37 & -9.95 & -4.01 & 0.25 & -3.68 & -3.38 & -7.06 & -5.46 & -0.13 & -5.98 \\
\hline & Stand 13 & -2.66 & -9.01 & -4.38 & 0.64 & -3.43 & -3.95 & -6.68 & -4.14 & -1.42 & -6.15 \\
\hline & Stand 16 & -3.35 & -11.96 & -4.84 & -0.37 & -4.03 & -3.76 & -8.32 & -6.31 & -0.98 & -8.01 \\
\hline \multirow[t]{4}{*}{ Basin } & Stand 5 & -0.57 & -8.73 & -3.05 & 2.15 & -1.64 & -4.23 & -7.53 & -4.85 & -1.69 & -7.11 \\
\hline & Stand 10 & -0.09 & -7.91 & -3.37 & 2.47 & -1.42 & -4.66 & -7.38 & -3.76 & -3.52 & -7.27 \\
\hline & Stand 11 & -0.11 & -7.90 & -2.48 & 2.71 & -1.13 & -4.11 & -7.48 & -5.11 & -1.96 & -7.05 \\
\hline & Stand 14 & -0.84 & -8.91 & -3.12 & 1.96 & -1.83 & -4.28 & -7.56 & -4.50 & -1.36 & -7.32 \\
\hline Gap & Stand 15 & -0.56 & -11.38 & -4.74 & 1.34 & -2.16 & -5.40 & -9.45 & -6.29 & -3.74 & -10.24 \\
\hline
\end{tabular}


de Souza Pereira, Kampel, and Cunha-Lignon: Mangrove vegetation structure in Southeast Brazil...

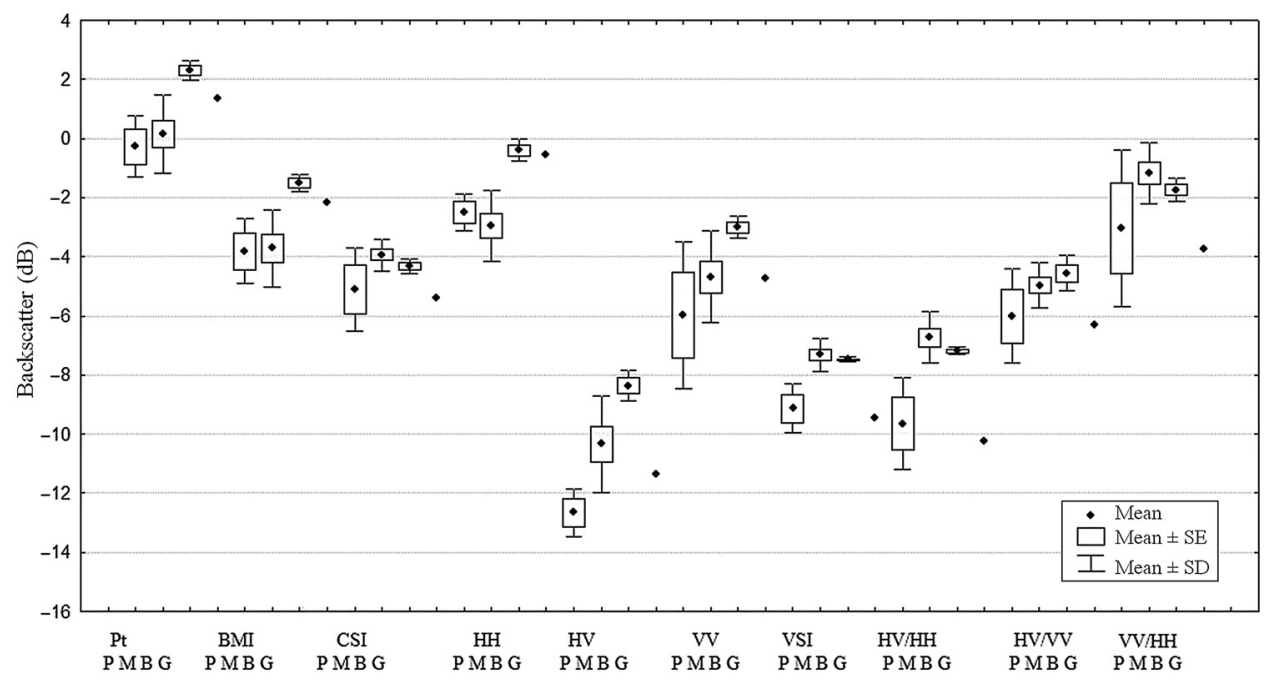

Fig. 3 Mean, standard deviation (SD), and standard error (SE) for SAR incoherent attributes backscatter values of physiographic mangrove types progradation $(P)$, mature $(M)$, basin $(B)$ and gap (G), (see text for acronyms).

demonstrated the potential to separate three physiographic types of mangrove. The VSI and HV/ $\mathrm{HH}$ allowed the discrimination of the progradation fringe from other types.

The Kruskal-Wallis and the multiple comparison tests (Table 5) allowed the statistical verification of the discrimination between physiographic mangrove types, considering structural development, using the incoherent attributes. Table 6 shows that the basin type differs from the mature fringe for $\mathrm{HH}$ and $\mathrm{BMI}$ attributes. For $\mathrm{HV}$ polarization, the basin type differs from the progradation fringe, and for VSI and $\mathrm{HV} / \mathrm{HH}$, the mature fringe differs from the progradation fringe.

Figure 4 shows the scatter plot of all incoherent attributes for 16 mangrove stands. Note that the basin was the physiographic mangrove type that provided a distinction from other physiographic types for $\mathrm{HH}, \mathrm{BMI}, \mathrm{HV}$, and $\mathrm{Pt}$.

\subsection{Regression Analysis}

Based on the premise that radar signals may be influenced by differences in the development of mangrove structure, ${ }^{21,-24}$ the incoherent attribute and biophysical parameters were correlated. According to the literature, ${ }^{22}$ the regression analysis has been used to investigate the relation

Table 5 Values of $\mathrm{H}$ and $p$ of Kruskal-Wallis test with $5 \%$ of significance (see text for acronyms).

\begin{tabular}{lcc}
\hline \hline SAR incoherent attributes & $\mathrm{H}$ & $p$ \\
\hline $\mathrm{HH}$ & 8.82 & 0.0121 \\
$\mathrm{HV}$ & 7.85 & 0.0197 \\
$\mathrm{VV}$ & 5.58 & 0.0613 \\
$\mathrm{Pt}$ & 6.96 & 0.0307 \\
$\mathrm{BMI}$ & 7.52 & 0.0233 \\
$\mathrm{CSI}$ & 2.65 & 0.2653 \\
$\mathrm{VSI}$ & 7.05 & 0.0295 \\
$\mathrm{HV} / \mathrm{HH}$ & 7.12 & 0.0284 \\
$\mathrm{HV} / \mathrm{VV}$ & 2.36 & 0.3069 \\
$\mathrm{VV} / \mathrm{HH}$ & 1.95 & 0.3772 \\
\hline \hline
\end{tabular}


Table 6 Multiple comparison test $p$ value between physiographic mangroves stand progradation $(P)$, mature $(M)$, and basin $(B)$. Statistically significant results are shown in bold.

\begin{tabular}{|c|c|c|c|c|}
\hline \multicolumn{2}{|c|}{ SAR incoherent attributes } & \multirow{2}{*}{$\frac{P}{-}$} & \multirow{2}{*}{$\frac{M}{1.0000}$} & \multirow{2}{*}{$\frac{B}{0.2630}$} \\
\hline HH & $\mathbf{P}$ & & & \\
\hline & M & 1.0000 & - & 0.0090 \\
\hline & B & 0.2630 & 0.0090 & - \\
\hline \multirow[t]{3}{*}{ HV } & $\mathbf{P}$ & - & 0.3798 & 0.0162 \\
\hline & $\mathbf{M}$ & 0.3798 & - & 0.2252 \\
\hline & B & 0.0162 & 0.2252 & - \\
\hline \multirow[t]{3}{*}{ VV } & $\mathbf{P}$ & - & 1.0000 & 0.0792 \\
\hline & M & 1.0000 & - & 0.1839 \\
\hline & B & 0.0792 & 0.1839 & - \\
\hline \multirow[t]{3}{*}{ PT } & $\mathbf{P}$ & - & 1.0000 & 0.0744 \\
\hline & M & 1.0000 & - & 0.0529 \\
\hline & B & 0.0744 & 0.0529 & - \\
\hline \multirow[t]{3}{*}{ BMI } & $\mathbf{P}$ & - & 1.0000 & 0.1014 \\
\hline & $\mathbf{M}$ & 1.0000 & - & 0.0278 \\
\hline & B & 0.1014 & 0.0278 & - \\
\hline \multirow[t]{3}{*}{ CSI } & $\mathbf{P}$ & - & 0.5323 & 1.0000 \\
\hline & M & 0.5323 & - & 0.6037 \\
\hline & B & 1.0000 & 0.6037 & - \\
\hline \multirow[t]{3}{*}{ VSI } & $\mathbf{P}$ & - & 0.0247 & 0.1711 \\
\hline & $\mathbf{M}$ & 0.0247 & - & 1.0000 \\
\hline & B & 0.1711 & 1.0000 & - \\
\hline \multirow[t]{3}{*}{$\mathrm{HV} / \mathrm{HH}$} & $\mathbf{P}$ & - & 0.0237 & 0.3911 \\
\hline & $\mathbf{M}$ & 0.0237 & - & 0.8814 \\
\hline & B & 0.3911 & 0.8814 & - \\
\hline \multirow[t]{3}{*}{ HV/VV } & $\mathbf{P}$ & - & 0.9653 & 0.3728 \\
\hline & $\mathbf{M}$ & 0.9653 & - & 1.0000 \\
\hline & B & 0.3728 & 1.0000 & - \\
\hline \multirow[t]{3}{*}{ VV/HH } & $\mathbf{P}$ & & 0.7430 & 1.0000 \\
\hline & $\mathbf{M}$ & 0.7430 & & 0.8199 \\
\hline & B & 1.0000 & 0.8199 & \\
\hline
\end{tabular}

between SAR backscatter and forest structure parameters. These correlations may be useful to understand the interaction of radar microwaves with forest components and help the interpretation of SAR images. Initially, exploratory analysis was conducted by correlating incoherent attributes and structural parameters. Table 7 presents the coefficients of correlation $R$ (Pearson) between 10 incoherent attributes and the mangrove structural parameters, such as mean DBH, 
de Souza Pereira, Kampel, and Cunha-Lignon: Mangrove vegetation structure in Southeast Brazil...

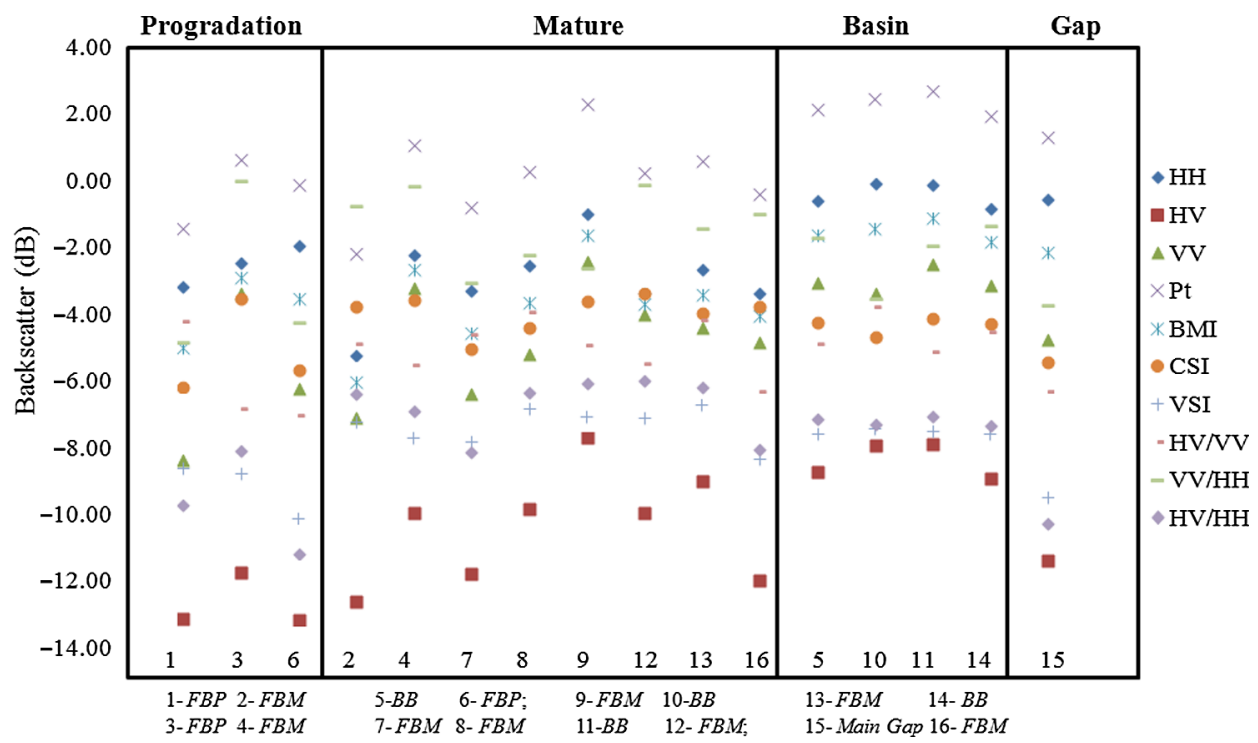

Fig. 4 Graphic of the SAR incoherent attributes backscatter of 16 mangrove stands. FBP, fringe in progradation; FBM, mature fringe; BB, basin stands.

Table 7 Pearson correlation coefficient $(R)$ between SAR incoherent attributes and structural parameters for 16 mangrove stands in the study area, with $95 \%$ of confidence.

\begin{tabular}{lccccc}
\hline \hline SAR incoherent attributes & Canopy height & Mean DBH & Basal area & Density & Mean height \\
\hline $\mathrm{HH}$ & -0.80 & -0.67 & -0.53 & 0.50 & -0.84 \\
$\mathrm{HV}$ & -0.43 & -0.14 & -0.47 & 0.07 & -0.59 \\
$\mathrm{VV}$ & -0.38 & -0.15 & -0.34 & 0.07 & -0.52 \\
$\mathrm{Pt}$ & -0.67 & -0.46 & -0.50 & 0.32 & -0.77 \\
$\mathrm{BMI}$ & -0.70 & -0.51 & -0.49 & 0.37 & -0.78 \\
$\mathrm{CSI}$ & 0.33 & 0.54 & 0.02 & -0.46 & 0.22 \\
$\mathrm{VSI}$ & 0.16 & 0.39 & -0.12 & -0.33 & 0.00 \\
$\mathrm{VV} / \mathrm{HH}$ & 0.34 & 0.50 & 0.10 & -0.40 & 0.31 \\
$\mathrm{HV} / \mathrm{HH}$ & 0.23 & 0.47 & -0.07 & -0.39 & 0.07 \\
$\mathrm{HV} / \mathrm{VV}$ & -0.13 & -0.01 & -0.14 & 0.04 & -0.19 \\
\hline \hline
\end{tabular}

canopy height, density (in logarithmic scale), basal area, and mean height. The results show a high correlation between HH polarization and mean tree height $(R=-0.84)$ and canopy height $(R=-0.80)$. These negative correlations showed higher backscatter for basin mangroves than for mature fringe mangroves. This result differs from some previous vegetation studies that showed a positive correlation between $\mathrm{HH}$ and tree height, ${ }^{26,28,29}$ probably because the forest structures are totally different in the present work for basin and fringe mangroves. This means that it is not only the height of tree that influences the backscatter, but the roots, bare soil, density of trunks, and tree configuration of these two physiographic types.

Multiple regression models were generated for each structural parameter and the function that presented higher $R^{2}$ and adjusted- $R^{2}$ values was chosen. Table 8 presents the best function results. Table 9 shows the PRESS and sum of squared error (SSE) value for each function. These results can be considered statistically valid. ${ }^{41}$ Figure 5 shows the graphics of the functions for mean DBH [Fig. 5(a)], canopy height [Fig. 5(b)], and mean height [Fig. 5(c)]. 
Table 8 Regression models for each structural parameter and the respective $R^{2}$ and adjusted- $R^{2}$ for canopy height, mean height, mean $\mathrm{DBH}$, basal area, and density.

\begin{tabular}{lccc}
\hline \hline Dependent variable & Linear regression function & $R^{2}$ & Adjusted- $R^{2}$ \\
\hline Canopy height & $=10.0787-2.1437 * \mathrm{BMI}+2.1489 * \mathrm{CSI}$ & 0.686 & 0.638 \\
Mean height & $=4.07041-1.34932 * \mathrm{BMI}+0.97938 * \mathrm{CSI}$ & 0.731 & 0.690 \\
Mean DBH & $=14.54714-1.80664 * \mathrm{BMI}+3.15292 * \mathrm{CSI}$ & 0.666 & 0.615 \\
Basal area & $=17.35489-4.54911 * \mathrm{HH}$ & 0.642 & 0.610 \\
Density & $=4.613352+0.229529 * \mathrm{HH}$ & 0.540 & 0.498 \\
\hline \hline
\end{tabular}

Table 9 The PRESS and SSE values and the percentage difference of these values.

\begin{tabular}{lccccc}
\hline \hline & Mean height & Mean DBH & Canopy height & Density & Basal area \\
\hline PRESS & 30.60 & 115.36 & 107.94 & 1.79 & 331.77 \\
SSE & 20.84 & 84.14 & 72.48 & 1.35 & 231.29 \\
$\%$ & 46.84 & 37.11 & 48.92 & 32.79 & 43.44 \\
\hline \hline
\end{tabular}

\subsection{Discussion}

In the present work, the mangrove under analysis presents different development stages—fringe progradation and fringe mature-and also differing physiographic types (such as basin and fringe), caused by environmental influences, such as geomorphology, freshwater input, and tidal influence. The SAR image backscatter for all polarizations and bands from different mangrove communities were investigated by Mitchell, ${ }^{22}$ and an influence of stand structure on the radar response was observed. According to this author, ${ }^{22}$ the SAR backscatter increased as a function of canopy height until the Rhizophora zone was reached, because this genus has many big exposed roots. In the present work, the HH backscatter presented higher values for the basin physiographic type than the mature fringe mangrove, thus, inverse correlation of $\mathrm{HH}$ and mean height (Table 7). This suggests other influences in the response of the radar not only on the height of trees, but also on variations of canopy structure, while the basin type has a lower height of tree and a high density of trunks and brunches, the mature fringe mangrove has a dense and closed canopy and big exposed roots. According to Mitchell, ${ }^{22}$ the magnitude of backscatter can be low when the mangrove has dense roots at the surface. Some mature mangroves with open canopies presented a high backscatter value, such as stand 9, which presents exposed (roots) rhizophores, inclined trunks, a presence of large bromeliads on tree trunks, and logs fallen in the soil. This characterization provides high penetration and interaction between radar microwaves and canopies/trees and soil components, promoting backscatter to the radar direction. The backscatter from the forest is dominated by components that promote reflection from the forest soil. ${ }^{29}$ In the HH polarization, the double bounce mechanism is dominant due to the trunk-soil interaction. The magnitude of backscatter coefficient varies with the root exposure system, e.g., rizophores of $R$. mangle and pneumatophores of A. schaeuriana and L. racemosa.$^{20}$ Additional explanations for higher HH backscatter from basin compared to the mature fringe are probably related to the attenuation dominated by the absorption of foliage and primary and secondary branches present in the tree crown and the roots in the soil for the mature fringe. In the basin, there are many secondary branches that contribute to scatter the energy. According to Proisy, ${ }^{24}$ mangroves with open canopies present higher backscatter values than mangroves with high biomass and closed canopies, mainly in $\mathrm{HH}$ polarization. The HV polarization shows variation according to differences in forest structure. ${ }^{21}$ High backscatter values of HV polarization may occur in vegetated areas with scattering from small elements and multiple scattering between surfaces. ${ }^{28}$ For HV polarization, backscatter increases from the fringe to the basin (Fig. 3). 

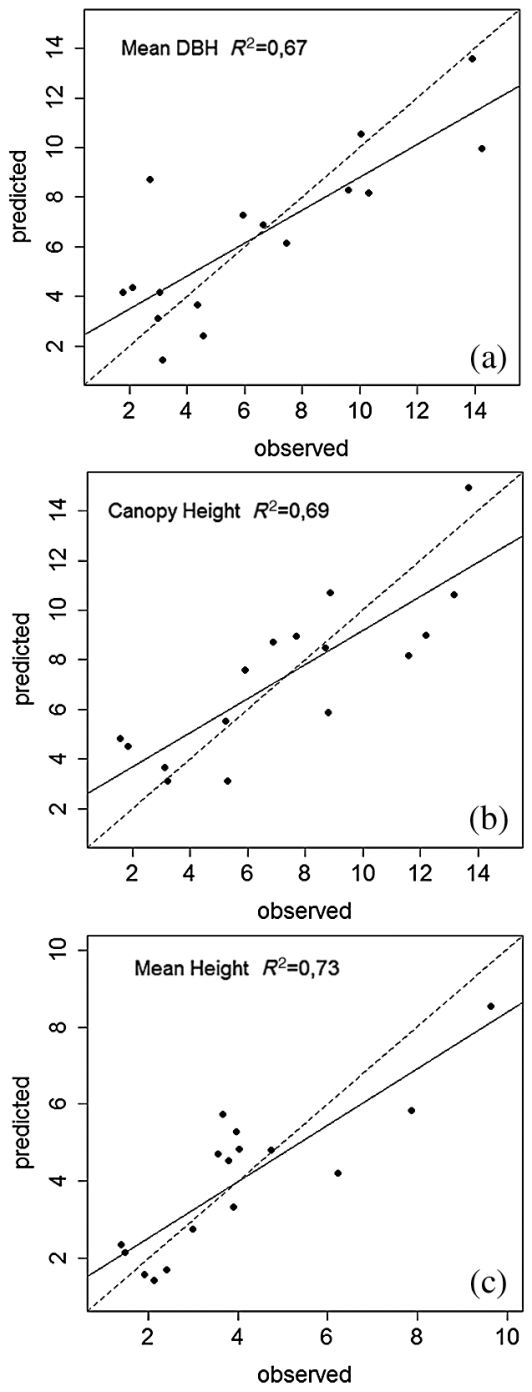

Fig. 5 Regression models results for (a) mean DBH, (b) canopy height, and (c) mean height, all using BMI and CSI parameters.

The parallel ratio (Rp) emphasizes differences between VV and $\mathrm{HH}$ sensitive scattering mechanisms. This parameter presented a higher mean value of backscatter for mature fringe mangroves, indicating the influence of big vertical trunks in the return signal. The cross polarization ratio (HV/ $\mathrm{HH})$ presented lower values for fringe and gap progradation. This parameter is sensitive to volume scatter events. The volume scatter mechanism probably occurs for the mature and basin physiographic mangrove types, which present higher values of backscatter. The radar wave's depolarization is the result of multiple scatters between vegetation components. ${ }^{21}$ The HV/VV backscatter mean value is lower for fringe progradation, indicating that the surface scatter mechanism is dominant, and for the mature forest and basin, the mean values of backscatter increase, suggesting microwave depolarization, canopy interaction, and volume scattering effects.

The L-band SAR interacts with primary and secondary branches and trunks, including the soil-trunk interaction, ${ }^{20}$ and is sensitive to the three-dimensional woody components. ${ }^{26}$ The penetration degree of the incident waves in the canopy depends on the density and structure of the vegetation components and gap presence. The total attenuation includes absorption and scattering loss. In L-band, volume scattering from the canopy is an important source of scattering, and the ability to penetrate through the canopy providing multiple interactions with vegetation components of other vegetation layers is also significant. ${ }^{42}$ The scatter mechanism model for the mangrove forest showed that double bounce is an indicator of the strong interaction between vegetation components, especially trunks and surface soil. ${ }^{23}$ Volume scattering dominates the 
responses of mature mangroves, which can be indicated by the $\mathrm{Rc}$ attribute. For band $\mathrm{C}$, the interactions of microwaves occur mainly with leaves and twigs. The use of a C-band and HV polarization of AIRSAR image allowed the different stages of mangrove development to be distinguished. ${ }^{21}$ Significant relationships between C-band RADARSAT-2 backscattering in $\mathrm{VH}$ polarization and structural attributes of regenerating mangrove vegetation were observed. ${ }^{27}$

The best multivariate regression models for tree canopy height $\left(R^{2}=0.69\right)$, mean tree height $\left(R^{2}=0.73\right)$, and mean DBH $\left(R^{2}=0.67\right)$ were obtained with the attributes BMI and CSI (Table 8). BMI and CSI are vegetation indices that have been related to forest structure. ${ }^{40}$ Both are formulated by $\mathrm{HH}$ and VV polarizations. The CSI index is a measure of the relative importance of vertical versus horizontal vegetation structure. ${ }^{40}$ The BMI and the CSI indices did not present a significant correlation $(R=0.17)$. The basin mangrove presented higher backscatter values for the BMI index. The basin mangrove normally has open canopies, a high density of individuals with many trunks, twigs, and twisted branches, which can contribute to backscatter for BMI. This index is correlated with wood biomass and trunks, and has higher values in forest that allow double bounce interaction due to corner reflections. ${ }^{40}$ This could be due to the behavior of the basin mangrove and some stands of the mature fringe, which have twisted trunks in the soil and open canopy, enabling corner reflection interaction with the signal. Forests dominated by vertical trunks and branches tend to have a high value for $\mathrm{CSI},{ }^{40}$ as can be verified in the mature fringe forest. In the present study for CSI, the mature fringe stands 12, 4, 13, and 9 presented higher backscatter values.

The regression model for basal area $\left(R^{2}=0.64\right)$ and density $\left(R^{2}=0.54\right)$ was constructed using only the $\mathrm{HH}$ polarization. Forests with a high basal area provide corner reflections of incident radiation. ${ }^{30}$ Flooded forests or forests with smooth soil can provide a high return signal to the radar. However, large basal areas can also cause low-trunk transmissivity. Due to the increase of the volume of leaves and branches of the canopies, it can scatter the radiation, provide attenuation, and decrease the backscatter, as observed in the mature fringe stands 2, 4, 8, and 12 . Density and DBH influenced transmissivity through the trunks. ${ }^{30}$ Dense and closed canopies increase the probability of radiation attenuation. Open canopies decrease the radiation interaction inside the canopies ${ }^{22}$ and provide soil-trunk interaction.

The backscatter from mangroves may differ due to flooding frequency, which can expose the surface and the roots of mangroves. In areas where the forest is flooded, the backscatter signal can be increased, especially in open canopy forests. This occurs due to the interaction of incident radiation with a reflecting surface or soil/trunk, causing double bounce interaction. At the time acquisition of the PALSAR image used in the present work, tide height was $0.9 \mathrm{~m}$ with soil and the pneumatophores (roots) of L. racemosa and A. schaueriana species covered by water, although the roots of $R$. mangle were probably not fully submerged. Soil covered by water provides higher specular signal responses of microwave interactions than when the roots are exposed. ${ }^{43}$ The use of the PALSAR L-band image with an incident angle of $25.7 \mathrm{deg}$ in high-tide condition seems to be favorable data to detect and map mangrove ecosystem, ${ }^{25}$ and also enables the identification of the different physiographic types of mangrove forests.

The structural differences of fringe and basin physiographic types were detected through SAR responses, principally for HH and HV polarization and for BMI. Based on the concept that the structural development of mangroves is a result of the maximum use of the available local energy, ${ }^{8}$ the present work shows that differences in mangrove zonation patterns, controlled by terrestrial surface drainage and local patterns of tides, can be studied and characterized with the use of L-band SAR backscatter information.

\section{Conclusions}

This work indicates that an L-band SAR image acquired in conditions of high tide, with an incidence angle of 25.7 deg allows the identification of different physiographic types and structural developments of mangrove forests. The results indicated that $\mathrm{HH}$ polarization and the BMI index can be used to discriminate fringe and basin physiographic types, whereas HV polarization showed a higher potential for discriminating mangrove forests with distinct structural 
development, such as fringes in progradation, mature fringes, and basins. The best results of the multiple linear regression models for canopy height, mean tree height, and mean DBH were obtained using BMI and CSI indices as explanatory variables. An increase in HH backscatter for open canopy forests was also observed in our study. Basin stands were the physiographic type that presented the highest backscatter values. From this, it is possible to infer that the stand aspects that had more influence on the returned radar signal are canopy openness, the existence of trunks fallen on the ground, low trees with many twigs, and twisted trees. The exposed roots (rhizophores) and the closed canopy of the mature fringe mangrove contribute to the absorption and attenuation of the SAR signal. Based on what was exposed, this study indicates that $\mathrm{HH}$ and $\mathrm{HV}$ polarizations are the most influential incoherent attributes to assist in discriminating mangrove forests with distinct structural developments and physiographic types.

The use of a multipolarized PALSAR image to get information on the physical characteristics of mangroves makes the L-band SAR a useful sensor for the structural characterization and discrimination of the distinct productivity of mangrove communities. This kind of information can contribute to the analysis of coastal environments, as well as being used for the monitoring of mangrove ecosystems, aimed at conservation, and for the sustainable use of its resources. For future studies, it is recommended to test different modes of image acquisition, one during high tide and other during low tide, in order to examine the influence of tide variation and associated flooding on SAR backscatter. Images with different incidence angles and frequencies should also be investigated to explore SAR's coherent parameters and to estimate mangrove biomass in this study region.

\section{Acknowledgments}

ALOS/PALSAR data were obtained from JAXA, under project ALOS RA\#219 "Geoscience Applications with L-Band PALSAR data in the Tropical Environment of Brazil" (Dr. Waldir Paradella, INPE). The Departamento de Águas e Energia Elétrica provided the planialtimetric charts. Pereira, FRS is funded by a fellowship from Coordenação de Aperfeiçoamento de Pessoal de Nível Superior (CAPES). Authors would like to thank Prof. Dr. Clemente Coelho Junior, from Universidade de Pernambuco (UPE), for providing in situ data, and Dr. Ricardo Menghini for his precious collaboration during field work. M.C.-L. has been studying mangrove forests since 1999, using permanent plots in the southern coast of São Paulo (Brazil). She provided structure vegetation data, analyzed, and discussed the results of the current paper with the first author. She contributed to improve this manuscript, focusing the mangrove forest aspects. M. K. was the doctorate supervisor of Francisca R. S. Pereira, supporting the development of her thesis and the present article. He participated in the proposition of the objectives, methodologies and in the analysis of results, having also helped to get the SAR image used in this work.

\section{References}

1. N. C. Duke et al., "A world without mangroves?," Science 317, 41-42 (2012).10.1126/ science.317.5834.41b

2. D. M. Alongi, "Mangrove forests: resilience, protection from tsunamis, and responses to global climate change," Estuar. Coastal Shelf Sci. 76(1), 1-13 (2008).

3. M. Cunha-Lignon et al., "Mangrove forests and sedimentary processes on the south coast of São Paulo State (Brazil)," J. Coastal Res. SI56, 405-409 (2009).

4. M. Cunha-Lignon et al., "Mangrove forests submitted to depositional processes and salinity variation investigated using satellite images and vegetation structure surveys," J. Coastal Res. 1(64), 344-348 (2011).

5. Y. Schaeffer-Novelli et al., "Variability of mangrove ecosystems along the Brazilian coast," Estuaries 13(2), 204-218 (1990).

6. N. C. Duke, M. C. Ball, and J. C. Ellison, "Factors influencing biodiversity and distributional gradients in mangroves," Global Ecol. Biogeogr. Lett. 7(1), $27-47$ (1998).

7. A. E. Lugo and S. C. Snedaker, "The ecology of mangroves," Annu. Rev. Ecol. Syst. 5(1), 39-64 (1974). 
8. Y. Schaeffer-Novelli et al., "Brazilian mangroves," Aquat. Ecosyst. Health Manage. 3(4), 561-570 (2000).

9. S. Sinha et al., "A review of radar remote sensing for biomass estimation," Int. J. Environ. Sci. Technol. 12(5), 1779-1792 (2015).

10. A. Aslan, "Mapping spatial distribution and biomass of coastal wetland vegetation in Indonesian Papua by combining active and passive remotely sensed data," Remote Sens. Environ. 183, 65-81 (2016).

11. Q. Man et al., "Light detection and ranging and hyperspectral data for estimation of forest biomass: a review," J. Appl. Remote Sens. 8(1), 081598 (2014).

12. F. Dahdouh-guebas, "The use of remote sensing and GIS in the sustainable management of tropical coastal ecosystems," Environ. Dev. Sustainability 4(9), 93-112 (2002).

13. D. Lagomasino et al., "A comparison of mangrove canopy height using multiple independent measurements from land, air, and space, Remote Sens. 8(4), 327 (2016).

14. C. Zhang et al., "Spectral response to varying levels of leaf pigments collected from a degraded mangrove forest," J. Appl. Remote Sens. 6(1), 063501 (2012).

15. C. Proisy, P. Couteron, and F. Fromard, Predicting and mapping mangrove biomass from canopy grain analysis using Fourier-based textural ordination of IKONOS images," Remote Sens. Environ. 109(3), 379-392 (2007).

16. C. Giri and J. Muhlhausen, "Mangrove forest distributions and dynamics in Madagascar (1975-2005)," Sensors 8(4), 2104-2117 (2008).

17. K. Zhang et al., "Airborne laser scanning quantification of disturbances from hurricanes and lightning strikes to mangrove forests in Everglades National Park, USA," Sensors 8(4), 2262-2292 (2008).

18. M. Simard et al., "A systematic method for 3D mapping of mangrove forests based on shuttle radar topography mission elevation data, ICEsat/GLAS waveforms and field data: application to Ciénaga Grande de Santa Marta, Colombia," Remote Sens. Environ. 112(5), 2131-2144 (2008).

19. T. E. Fatoyinbo and M. Simard, "Height and biomass of mangroves in Africa from ICESat/ GLAS and SRTM," Int. J. Remote Sens. 34(2), 668-681 (2013).

20. R. M. Lucas, "The potential of L-band SAR for quantifying mangrove characteristics and change: case studies from the tropics," Aquatic Conserv. Mar. Freshwater Ecosyst. 17(3), 245-264 (2007).

21. E. Mougin et al., "Multifrequency and multipolarization radar backscattering from mangrove forests," IEEE Trans. Geosci. Remote Sens. 37(1), 94-102 (1999).

22. A. L. Mitchell, Remote Sensing Techniques for Assessment of Mangrove Forest Structure, Species Composition and Biomass and Response to Environmental Change, University of New South Wales, Sydney, Australia (2003).

23. C. Proisy et al., "Interpretation of polarimetric radar signatures of mangrove forests," Remote Sens. Environ. 71(2), 56-66 (2000).

24. C. Proisy et al., "On the influence of canopy structure on the radar backscattering of mangrove forests," Int. J. Remote Sens. 23(20), 4197-4210 (2002).

25. F. Rocha de Souza Pereira, M. Kampel, and M. Cunha-Lignon, "Mapping of mangrove forests on the southern coast of São Paulo, Brazil, using synthetic aperture radar data from ALOS/PALSAR,” Remote Sens. Lett. 3(7), 567-576 (2012).

26. R. Lucas et al., "Contribution of L-band SAR to systematic global mangrove monitoring," Mar. Freshwater Res. 65(7), 589-603 (2014).

27. M. Cougo et al., "Radarsat-2 backscattering for the modeling of biophysical parameters of regenerating mangrove forests," Remote Sens 7(12), 17097-17112 (2015).

28. D. G. Leckie and K. J. Ranson, "Forestry applications using imaging radar," in Manual of Remote Sensing: Principles and Applications of Imaging Radars, 3rd ed., F. M. Henderson and A. J. Lewis, Eds., p. 866, John Wiley and Sons, Inc., New York (1998).

29. J. A. Richards, P. W. Woodgate, and A. K. Skidmore, "An explanation of enhanced radar backscattering from flooded forests," Int. J. Remote Sens. 8(7), 1093-1100 (1987).

30. P. A. Townsend, "Estimating forest structure in wetlands using multitemporal SAR," Remote Sens. Environ. 79(2-3), 288-304 (2002). 
31. C. Coelho, Jr., "Ecologia de manguezais: zonação e dinâmica da cobertura vegetal em gradientes ambientais," Doctoral Thesis, p. 166, IOUSP, University of São Paulo, Cananéia, São Paulo, Brasil (2003).

32. M. Cunha-Lignon, "Characterisation of mangrove forest types in view of conservation and management: a review of mangals at the Cananéia region São Paulo State, Brazil," J. Coastal Res. SI64, 349 (2011).

33. G. Cintrón and Y. Schaeffer-Novelli, "Methods for studying mangrove structure," in The Mangrove Ecosystem: Research Methods, S. C. Snedaker and J. Snedaker, Eds., pp. 91-113, UNESCO, Paris, France (1984).

34. Instituto Nacional De Meteorologia (INMET), "Dados de chuva acumulada em 24 h,” 2010, http://www.inmet.gov.br/html/observacoes.php?lnk=Gr\%E1ficos (2 September 2012).

35. F. M. Henderson and A. J. Lewis, Manual of Remote Sensing: Principles and Applications of Imaging Radars, 3rd ed., John Wiley and Sons, New York (1998).

36. J. Jong-Sen Lee, M. R. Grunes, and G. de Grandi, "Polarimetric SAR speckle filtering and its implication for classification," IEEE Trans. Geosci. Remote Sens. 37(5), 2363-2373 (1999).

37. A. Rosenqvist et al., "ALOS PALSAR: a pathfinder mission for global-scale monitoring of the environment," IEEE Trans. Geosci. Remote Sens. 45(11), 3307-3316 (2007).

38. National Spatial Data Infrastructure-NSDI, "Geospatial positioning accuracy standards: part 3-national standard for spatial data accuracy," Reston: USGS, 1998, https://www.fgdc.gov/ standards/projects/accuracy/part3/chapter3 (22 April 2015).

39. M. Shimada et al., "PALSAR radiometric and geometric calibration," IEEE Trans. Geosci. Remote Sens. 47(12), 3915-3932 (2009).

40. K. O. Pope, J. M. Rey-Benayas, and J. F. Paris, "Radar remote sensing of forest and wetland ecosystems in the Central American tropics," Remote Sens. Environ. 48(2), 205-219 (1994).

41. J. Neter et al., Applied Linear Statistical Models, 4th ed., McGraw-Hill, Boston, Massachusetts (1996).

42. M. Simard et al., "Mapping tropical coastal vegetation using JERS-1 and ERS-1 radar data with a decision tree classifier," Int. J. Remote Sens. 23(7), 1461-1474 (2002).

43. M. Imhoff et al., "Forest canopy characterization and vegetation penetration assessment with space-borne radar," IEEE Trans. Geosci. Remote Sens. 24(4), 535-542 (1986).

Francisca Rocha de Souza Pereira graduated in geography at Federal University of Santa Catarina. She is a PhD student at INPE's graduate program in remote sensing, Brazil, where she also obtained her master's degree. Her topics of interests are mapping, monitoring, and management of mangroves and coastal zones using remote sensing SAR, LiDAR, and optical data.

Milton Kampel graduated in oceanography, has a master's in remote sensing/geosciences, and a DSc in biological oceanography. He is a senior researcher and professor at Earth Observation branch, INPE. He is a specialist in satellite oceanography, with interest in topics such as marine ecosystem monitoring (mangroves, coral reefs), phytoplankton biomass and primary production, biophysical interactions, and coastal management.

Marília Cunha-Lignon graduated in biology from Universidade do Estado do Rio de Janeiro (1991), has a master's at Biologie du Comportement from Université Paris XIII (1994), a master's in oceanography from Universidade de São Paulo (2001), and her PhD in oceanography from Universidade de São Paulo (2005). She is a full-time professor and researcher at Universidade Estadual Paulista. She has experience in oceanography, tropical coastal wetlands, focusing on mangrove, conservation, coastal management, and geotechnologies. 